\title{
Impact of sex on outcomes after percutaneous repair of functional mitral valve regurgitation
}

\author{
Vincent Chan ${ }^{1}$, David Messika-Zeitoun ${ }^{1}$, Marino Labinaz ${ }^{1}$, Mark Hynes ${ }^{1}$, Donna \\ Nicholson $^{1}$, Adam Dryden ${ }^{2}$, Thierry Mesana ${ }^{2}$, and Ben Hibbert ${ }^{2}$ \\ ${ }^{1}$ University of Ottawa Heart Institute \\ ${ }^{2}$ Affiliation not available
}

January 25, 2021

\begin{abstract}
Background The role of percutaneous repair of functional mitral regurgitation (MR) is evolving. Left ventricle remodeling is known to be different between men and women; however, outcomes following percutaneous repair of functional MR have not considered the impact of sex. Methods Between 2012 and 2018, 175 patients underwent percutaneous repair of functional MR with the Mitra Clip NT/NTR (Abbott, Irvine CA) at our institution. Patients were assessed in a dedicated clinic with a follow-up that averaged $0.7 \pm 1.2$ years and extended to 5.7 years. Results Men had a larger body surface area than women $(\mathrm{p}<0.001)$, whereas women were more likely than men to have diabetes preoperatively $(\mathrm{p}=0.02)$. There were no deaths or instances of single leaflet detachment. Immediate post-procedure MR was $<2+$ in $158(90 \%)$ with a mean trans-mitral valve repair gradient of $3.4 \pm 1.0$ and $3.5 \pm 2.1 \mathrm{~mm} \mathrm{Hg}$, respectively for women and men $(\mathrm{p}=0.8)$. One- and 2-year freedom from MR $>3+$ was $86.0 \pm 3.5 \%$ and $77.6 \pm 5.1 \%$, respectively. After adjusting for differences between male and female patients, women were more likely to have recurrent $\mathrm{MR}>3+$ (hazard ratio 4.7, 95\% confidence interval 1.2-18.4, $\mathrm{p}=0.03$ ). Upon adjusted analysis, there was also no association between gender and survival $(\mathrm{p}=0.2)$. One- and 2- year survival was $69.8 \pm 4.3 \%$ and $54.3 \pm 5.5 \%$, respectively. Conclusion Women are more likely to have recurrent severe MR after percutaneous repair of functional MR. The mechanism for this remains undetermined.
\end{abstract}

\section{Hosted file}

Clip Sex Oct 2020_JCS.pdf available at https://authorea.com/users/391712/articles/505742impact-of-sex-on-outcomes-after-percutaneous-repair-of-functional-mitral-valve-

regurgitation 